"This document is the Accepted Manuscript version of a Published Work that appeared in final form in The Journal of Physical Chemistry A, copyright $(\mathcal{C}$ American Chemical Society after peer review and technical editing by the publisher. To access the final edited and published work see https://pubs-acs-org.uml.idm.oclc.org/doi/10.1021/acs.jpca.8b06731”.

\title{
Isothiocyanato-Containing Carbon Chains: The Laboratory Detection of HCCCCNCS and NCCCNCS via Rotational Spectroscopy
}

Wenhao Sun and Jennifer van Wijngaarden*

Department of Chemistry, University of Manitoba, Winnipeg, Manitoba, R3T 2N2, Canada

*Corresponding author

Email: vanwijng@cc.umanitoba.ca

Phone: (204)474-8379

Fax: (204)474-7608 


\begin{abstract}
Two new NCS-containing carbon chains of potential astronomical interest, $\mathrm{HC}_{4} \mathrm{NCS}$ and $\mathrm{NC}_{3} \mathrm{NCS}$, were produced through dc electric discharge in a molecular beam and detected by Fourier transform microwave spectroscopy. Rotational transitions from the two species were recorded between 4 and $26 \mathrm{GHz}$ and assignments were confirmed by the distinct hyperfine structures due to the ${ }^{14} \mathrm{~N}$ nuclear quadrupole moments of these two linear, isoelectronic species. The rotational constants of $\mathrm{HC}_{4} \mathrm{NCS}$ and $\mathrm{NC}_{3} \mathrm{NCS}$ were determined experimentally to be 595.09300(3) MHz and 596.26344(2) MHz, respectively and are in good agreement with theoretical predictions at the MP2 and $\operatorname{CCSD}(\mathrm{T})$ levels of theory. The use of diacetylene in the precursor mixture to form $\mathrm{HC}_{4} \mathrm{NCS}$ improved the intensity of the spectrum by a factor of ten and allowed the observation of the rotational transitions of the ${ }^{34} \mathrm{~S}$ singly substituted form in natural abundance.
\end{abstract}




\section{Introduction}

Interstellar molecular clouds and circumstellar shells are rich environments where many chemical reactions take place and over 200 molecular species have been identified in the gas phase. ${ }^{1}$ The astronomical detection of these molecular species through spectroscopy in the radio, microwave and infrared regions can help scientists understand the chemical and physical processes of the formation and evolution of astrophysical objects. To facilitate the unambiguous identification of new species in space, their spectral signatures should be well-characterized from laboratory work. NCS-containing molecules have been the subject of investigation in the laboratory since the interstellar detection of hydrogen isothiocyanate, $\mathrm{HNCS}^{2}$ toward the Sagittarius B2 (Sgr B2) molecular cloud in 1979 based on its signature rotational spectrum. ${ }^{3}$ Thirty years later, the higher energy isomer, thiocyanic acid HSCN, was also identified in Sgr $\mathrm{B} 2^{4}$ after laboratory measurements of its rotational spectrum in both the centimeter-wave and millimeter-wave bands. ${ }^{5}$ Interestingly, the column density of HSCN in this molecular cloud $\left(T_{\text {rot }} 19 \pm 2 \mathrm{~K}\right)$ is only about one third that of the most stable isomer HNCS although the former is predicted to be significantly higher in energy $(\sim 6.6 \mathrm{kcal} / \mathrm{mol})$ from various levels of

calculation theory ${ }^{6-8}$ demonstrating that thermodynamics alone is not a reliable indicator of abundance. In 2016, the laboratory rotational spectra of the two higher energy remaining isomers, 
HCNS and HSNC were comprehensively studied by McGuire et al. ${ }^{8}$ via rotational spectroscopy and both species await astronomical detection.

A survey of known interstellar molecules reveals that many of the heavier species detected in the gas phase are polyynic or cumulenic carbon chains containing a heteroatom such as N, O or S. For example, cyano-containing carbon chains of $\mathrm{H}-(\mathrm{C} \equiv \mathrm{C})_{\mathrm{n}}-\mathrm{CN}(\mathrm{n}=0 \ldots 4)^{9-17}$ have been identified with the smaller versions, $\mathrm{HC}_{3} \mathrm{~N}^{10}$ and $\mathrm{HC}_{5} \mathrm{~N}^{13}$ reported in $\mathrm{Sgr} \mathrm{B} 2$ along with HNCS and HSCN. The recent laboratory detection of the pure rotational spectrum of ethynyl isothiocyanate HCCNCS in both the ground state and an excited bending state using Fourier transform microwave spectroscopy ${ }^{18}$ is the first report of a carbon chain containing the NCS functional group. Based on the observed spectrum and high level coupled cluster calculations, HCCNCS is effectively a linear molecule in the ground vibrational state and is described by a very broad, flat potential well along the CNC coordinate in contrast to HNCS which is bent at the site of both nitrogen with $\angle \mathrm{HNC}=131.0^{\circ}$ and carbon with $\angle \mathrm{NCS}=187.3^{\circ} .{ }^{8}$ By comparison, the pure rotational and vibrational spectra of cyanogen isothiocyanate NCNCS, which is the isoelectronic analog of HCCNCS, has already been well-studied in the microwave, millimeter wave and far infrared region ${ }^{19-22}$ and has a bent equilibrium geometry. As a prototypical example of quantum monodromy, its ground state and multiple bending states are below the barrier to linearity, while it becomes a linear molecule in higher vibrational states above the monodromy point. Based on current known interstellar molecules, longer chain NCS-containing molecules are plausible candidates for future detection and their observation would provide important input for astronomical models.

Here we report the first laboratory study of the ground state rotational spectra of $\mathrm{HC}_{4} \mathrm{NCS}$ and $\mathrm{NC}_{3} \mathrm{NCS}$, using Balle-Flygare Fourier transform microwave (FTMW) spectroscopy. To 
obtain the title molecules, different mixtures of precursor gases were used in conjunction with a dc discharge assembly which is coupled with a pulsed solenoid nozzle. The two newly observed molecular species have a very similar pattern of transitions owing to their comparable moments of inertia but the observed hyperfine structure of the transitions is unique due to the different number of ${ }^{14} \mathrm{~N}$ nucleus in the molecules. In addition, the rotational transitions of the ${ }^{34} \mathrm{~S}$ substituted species of $\mathrm{HC}_{4} \mathrm{NCS}$ were observed in natural abundance. The experimentally derived spectroscopic constants are in favorable agreement with those from theoretical calculations.

\section{$\underline{\text { Experimental details }}$}

The two longer chain NCS-containing species were produced by applying an electric discharge of $750 \mathrm{~V}$ to gas mixtures containing suitable precursors during supersonic expansion. The details of the discharge nozzle assembly are described elsewhere. ${ }^{18}$ The precursors used to make $\mathrm{HC}_{4} \mathrm{NCS}$ in the discharge plasma were methyl isothiocyanate $\left(\mathrm{CH}_{3} \mathrm{NCS}\right)$ and diacetylene $\left(\mathrm{HC}_{4} \mathrm{H}\right) . \mathrm{CH}_{3} \mathrm{NCS}$ is commercially available and solid at room temperature (mp: $30-34{ }^{\circ} \mathrm{C}$ ). The sample (97\%) was purchased from Sigma-Aldrich and used without further purification. A few milliliters of sample were placed in a glass vessel seated in a mild water bath maintained at $37^{\circ} \mathrm{C}$. The gas sample of diacetylene was prepared through a one-step reaction ${ }^{23}$ and captured in a small stainless steel cylinder. A gas mixture of $0.5 \%$ diacetylene diluted in the carrier gas $\mathrm{Ne}$ was used then bubbled through the liquid $\mathrm{CH}_{3} \mathrm{NCS}$ sample and delivered to the spectrometer with a nozzle backing pressure of $\sim 1 \mathrm{~atm}$. This mixture produced detectable quantities of $\mathrm{HC}_{4} \mathrm{NCS}$ at the $7 \mathrm{~Hz}$ repetition rate of the pulsed discharge nozzle while attempts to use commercially available acetylene reduced the intensity of the observed transitions to about 1/10 that from the diacetylene mixture. In order to produce $\mathrm{NC}_{3} \mathrm{NCS}$, a precursor mixture of $0.5 \%$ acetonitrile $\left(\mathrm{CH}_{3} \mathrm{CN}, 99.8 \%\right.$, purchased from Sigma-Aldrich) and $0.5 \%$ acetylene $(\mathrm{HCCH})$ in Ne was seeded with the $\mathrm{CH}_{3} \mathrm{NCS}$ using the same setup. 
The University of Manitoba Balle-Flygare Fourier transform microwave (FTMW) spectrometer ${ }^{24}$ was used to survey for the rotational transitions of these two target species with a scanning step size of $0.25 \mathrm{MHz}$. The spectral linewidths with this instrument are typically $\sim 7$ $\mathrm{kHz}(\mathrm{FWHM})$ which makes it possible to routinely resolve hyperfine components from the ${ }^{14} \mathrm{~N}$ nuclear quadrupole moment. The identification of the two linear species was confirmed by the experimental $B_{0}$ rotational constants and the characteristic ${ }^{14} \mathrm{~N}$ nuclear hyperfine structure. Once the first transitions were observed, the molecular source conditions were optimized and the remaining rotational transitions were collected in the range of $4-26 \mathrm{GHz}$; the accuracy of the frequencies is typically measured to within $\pm 2 \mathrm{kHz}$. The rotational spectrum of ${ }^{34} \mathrm{~S}$ substituted $\mathrm{HC}_{4} \mathrm{NCS}$ species was observed in natural abundance to further confirm the assignment but the signal intensity of $\mathrm{NC}_{3} \mathrm{NCS}$ was insufficient to observe transitions of its minor isotopologues.

\section{Theoretical methods}

The equilibrium structures of $\mathrm{HC}_{4} \mathrm{NCS}$ and $\mathrm{NC}_{3} \mathrm{NCS}$ were found by first optimizing the geometries at the MP2/cc-pVQZ level of theory using Gaussian 09 software..$^{25}$ To investigate the $\mathrm{CNC}$ bending potential energy curves about these minima, a series of MP2 single point calculations were performed by varying the $\mathrm{CNC}$ angle from $175^{\circ}$ to $180^{\circ}$ with a step size of one degree. For each point, the chosen value for the $\mathrm{CNC}$ angle was kept constant while all other structural parameters were optimized. The potential energy curves confirmed that both species are linear rather than quasilinear as observed at the same level of theory for HCCNCS owing to its very flat potential. ${ }^{18}$ The results are shown in Figure 1. Coupled-cluster calculations with the $\operatorname{CCSD}(\mathrm{T})$ method were then carried out with the cc-pVTZ basis set using the ORCA program ${ }^{26,27}$ and provided further confirmation of the linear configuration of both chains. A summary of the calculated rotational constants, ${ }^{14} \mathrm{~N}$ nuclear quadrupole coupling constants and permanent 
electric dipole moment of $\mathrm{HC}_{4} \mathrm{NCS}$ and $\mathrm{NC}_{3} \mathrm{NCS}$ at both levels of theory is shown in Table 1 and the equilibrium structures and the relative energies along the $\mathrm{CNC}$ potential energy curves are provided as Supplementary Information.

\section{$\underline{\text { Results and analysis }}$}

As expected based on the computational results, the rotational spectra observed for both $\mathrm{HC}_{4} \mathrm{NCS}$ and $\mathrm{NC}_{3} \mathrm{NCS}$ were those of a linear molecule with regularly spaced transitions. A total of 17 rotational transitions $\left(J^{\prime \prime}=3-19\right)$ were recorded for the $\mathrm{HC}_{4} \mathrm{NCS}$ parent and the observed frequencies are listed in Table 2. The Balle-Flygare FTMW spectrometer was able to resolve ${ }^{14} \mathrm{~N}$ hyperfine structure for those with $J$ " values less than 9. A sample spectrum of the resolved hyperfine structure (hfs) of the $J^{\prime}-J^{\prime \prime}=6-5$ transition is provided in Figure 2. The full set of observed transitions was fit using Pickett's SPFIT program. ${ }^{28}$ The resulting spectroscopic constants are reported in Table 3. The ${ }^{14} \mathrm{~N}$ nuclear quadrupole coupling constant $e Q q, 2.27(6)$ $\mathrm{MHz}$, is in favourable agreement with the ab initio values in Table 1. Rotational transitions of the ${ }^{34} \mathrm{~S}$ substituted species were well-predicted by scaling the experimental $B_{0}$ constant of the parent species. In total, 8 rotational transitions were collected for the ${ }^{34} \mathrm{~S}$ species and fit in the same way as the parent. The rms error of each fit falls below $2 \mathrm{kHz}$.

As $\mathrm{NC}_{3} \mathrm{NCS}$ needs molecular fragments from three precursors $\mathrm{CH}_{3} \mathrm{NCS}, \mathrm{CH}_{3} \mathrm{CN}$ and $\mathrm{HCCH}$ for formation in the jet, the intensity of its rotational transitions was very low and only about 1/10 that of $\mathrm{HC}_{4} \mathrm{NCS}$ despite the larger predicted dipole moment at all levels of theory (Table 1). Due to the presence of two ${ }^{14} \mathrm{~N}$ nuclear quadrupole moments, there are more hyperfine components for each rotational transition, which provides a convenient means to confirm the observation of this long chain analog of $\mathrm{HC}_{4} \mathrm{NCS}$. In total, 15 rotational transitions $\left(J^{\prime \prime}=3-19\right)$ were recorded and the ${ }^{14} \mathrm{~N}$ hyperfine structure was resolved and assigned for two. The $J^{\prime}-J^{\prime \prime}=5$ - 
4 and 8-7 rotational transitions were not observed as they were overshadowed by intense spectral lines of the precursors. The assignment was made using quantum numbers corresponding to the coupling scheme:

$\overrightarrow{F_{1}}=\vec{J}+\overrightarrow{I_{1}}, \quad \overrightarrow{F_{2}}=\vec{F}_{1}+\overrightarrow{I_{2}}$

where $\mathrm{I}_{1}$ refers to the ${ }^{14} \mathrm{~N}$ in $\mathrm{NCS}$ and $\mathrm{I}_{2}$ refers to the $\mathrm{NC}$ fragment. The observed frequencies are summarized in Table 4. The rms error of the global fit is $1.29 \mathrm{kHz}$ using the SPFIT program. The experimentally determined parameters including the two ${ }^{14} \mathrm{~N}$ nuclear quadrupole coupling constants are provided in Table 3 . The two quadrupole hyperfine constants, $e Q q(N C)$ and $e Q q(N C S)$, are in good agreement with the ab initio results in Table 1 given the difficulty in assigning the complex splitting pattern. A sample spectrum of the $J^{\prime}-J^{\prime \prime}=7-6$ hyperfine transitions along with a simulated spectrum from the fit spectroscopic constants is shown in Figure 3.

\section{$\underline{\text { Discussion }}$}

The ground state rotational constants $\left(\mathrm{B}_{0}\right)$ of $\mathrm{HC}{ }_{4} \mathrm{NCS}$ and $\mathrm{NC}_{3} \mathrm{NCS}$ are within $2 \%$ of those predicted by the ab initio calculations $\left(\mathrm{B}_{\mathrm{e}}\right)$ lending support to the assignment and the assertion that these molecules are indeed linear. Hyperfine structure from the ${ }^{14} \mathrm{~N}$ nucleus was resolved for both molecules for several low $J$ rotational transitions, as illustrated in Figure 2 and Figure 3, and the patterns are consistent with the calculated values. Furthermore, transitions for

${ }^{34} \mathrm{~S}$ singly substituted $\mathrm{HC}_{4} \mathrm{NCS}$, observed in natural abundance, provide further confirmation of the observation of this new species. For $\mathrm{NC}_{3} \mathrm{NCS}$, the signal intensity was too low to observe minor isotopologues in natural abundance, however, the identification was substantiated by testing the parent signal response to turning the discharge off, and to removing $\mathrm{CH}_{3} \mathrm{NCS}$ and 
$\mathrm{CH}_{3} \mathrm{CN}$ from the precursor mixture. A survey of an extra $200 \mathrm{MHz}$ on each side of the most intense parent transitions $\left(J^{\prime}-J^{\prime \prime}=10-9\right.$ for $\mathrm{HC}_{4} \mathrm{NCS}, J^{\prime}-J^{\prime \prime}=15-14$ for $\left.\mathrm{NC}_{3} \mathrm{NCS}\right)$ was carried out to search for transitions involving excited levels of the bending modes as was reported for $\mathrm{HCCNCS}^{18}$ but no additional transitions were found. This is likely due to the low intensity of even the ground state transitions which required averaging thousands (and tens of thousands) of FIDs for observation.

As reported previously, HCCNCS is effectively a linear molecule despite the fact that its isoelectronic analogue $\mathrm{NCNCS}$ is bent $\left(\angle \mathrm{NCN}=183.5^{\circ}, \angle \mathrm{CNC}=143.0^{\circ}\right.$ and $\left.\angle \mathrm{NCS}=185.4^{\circ}\right)$ in the ground vibrational state. ${ }^{20}$ With the elongation of the carbon chain by one $\mathrm{C} \equiv \mathrm{C}$ triple bond, both $\mathrm{HC}_{4} \mathrm{NCS}$ and $\mathrm{NC}_{3} \mathrm{NCS}$ are predicted to be linear at the MP2/cc-pVQZ level. To confirm that the geometries are linear (rather than quasilinear), the $\mathrm{CNC}$ bending potential energy curves were computed. The curves are presented in Figure 1 and neither reveal a barrier at $\angle \mathrm{CNC}$ $=180^{\circ}$. This trend towards linearity at nitrogen with increasing carbon chain length is consistent with the reported geometries of related species. For example, the angle at the nitrogen atom increases from $\mathrm{HNCO}\left(\angle \mathrm{HNC}=128.0^{\circ}\right)^{29}$ to $\mathrm{HCCNCO}\left(\angle \mathrm{CNC}=170.02^{\circ}\right)^{30}$ and also from HNCS $\left(\angle \mathrm{HNC}=131.0^{\circ}\right)^{8}$ to $\mathrm{HCCNCS}\left(\angle \mathrm{HNC}=180^{\circ}\right) .{ }^{18}$ This change in geometry is compatible with increased sp-character on the nitrogen atom of the isothiocyanato-moiety presumably due to increased stabilization from conjugation with the added alkyne subunits. The same trend is observed for the cyano-terminated chains with $\mathrm{NC}_{3} \mathrm{NCS}$ being linear and $\mathrm{NCNCS}$ having $\angle \mathrm{CNC}=143.0^{\circ} .{ }^{20}$

For closed-shell linear molecules, the mathematical relationship between $B_{0}$ and $D_{0}$ as a function of carbon chain length $\mathrm{L}$ has been explored by Thaddeus et al. ${ }^{31} \mathrm{In}$ this work, they invoked a semi-classical theory to treat multiple series of carbon chain molecules as elastic rods 
with cross-sectional area $\sigma$, density per unit length $\rho$ and a common Young's modulus E to derive an expression for the energy levels of a rigid rotor as a function of $\mathrm{L}$ with a correction term for non-rigidity due to elastic deformation of the rod. In this model, the ratio of the centrifugal distortion constant to the rotational constant $\left(D_{0} / B_{0}\right)$ has a $\mathrm{L}^{-4}$ dependence such that a plot of $\log \left(D_{0} / B_{0}\right)$ versus $\log (\mathrm{L})$ yields a straight line with a slope of -4 . As proof of concept, they

plotted the experimental spectroscopic constants from more than 20 different carbon chain species, such as $\mathrm{HC}_{2 \mathrm{n}+1} \mathrm{~N}^{31,32}$ and $\mathrm{CH}_{3} \mathrm{C}_{2 \mathrm{n}} \mathrm{CH},{ }^{33}$ and found strong agreement with this model. In Figure 4, the $\log \left(D_{0} / B_{0}\right)$ of $\mathrm{HC}_{4} \mathrm{NCS}$ and $\mathrm{NC}_{3} \mathrm{NCS}$ versus $\log (\mathrm{L})$ are plotted together with those of $\mathrm{HC}_{2 \mathrm{n}+1} \mathrm{~N}(\mathrm{n}=1 \ldots 5)$ for comparison where $\mathrm{L}$ is estimated from the $\mathrm{CCSD}(\mathrm{T})$ geometry $\left(\mathrm{HC}_{4} \mathrm{NCS}\right.$ and $\left.\mathrm{NC}_{3} \mathrm{NCS}\right)$ or from the experimental structure $\left(\mathrm{HC}_{2 \mathrm{n}+1} \mathrm{~N}(\mathrm{n}=1 \ldots .5)\right)^{34}$ and the slope shown is the theoretical value of -4 . It is seen that $\mathrm{HC}_{4} \mathrm{NCS}$ falls on the linear trend while the data for $\mathrm{NC}_{3} \mathrm{NCS}$ gives rise to a positive deviation which is a result of the experimental $D_{0}$ constant that is 2.6 times larger than that of its isoelectronic counterpart $\mathrm{HC}_{4} \mathrm{NCS}$. This unusually large $D_{0}$ constant is likely a consequence of the flatter potential for $\mathrm{NC}_{3} \mathrm{NCS}$ along the $\mathrm{CNC}$ bending coordinate as reported in Figure 1 which should give rise to a lower frequency bending vibration and a more fluxional rod.

\section{Conclusion}

In closing, the present study reports the successful production of two new carbon chain species, $\mathrm{HC}_{4} \mathrm{NCS}$ and $\mathrm{NC}_{3} \mathrm{NCS}$, using electric discharge and their pure rotational spectra in the ground state through microwave spectroscopy. Even though these two molecules have the same number of electrons and have very similar moments of inertia, the hyperfine splitting patterns due to the ${ }^{14} \mathrm{~N}$ quadrupolar nuclei are unique because of the different number of nitrogen atoms. Combined with theoretical calculations, the rotational spectra with the resolved hyperfine 
structures confirm the linear geometries for these species. As cyano-substituted polyynes and HNCS are known astronomical molecules, the present carbon chain species serve as potential future targets for observation in the centimeter wave range.

\section{Supporting Information}

Equilibrium structures of $\mathrm{HC}_{4} \mathrm{NCS}$ and $\mathrm{NC}_{3} \mathrm{NCS}$ (Tables S1-S4)

Relative energies of $\mathrm{HC}_{4} \mathrm{NCS}$ and $\mathrm{NC}_{3} \mathrm{NCS}$ (Table S5)

\section{Acknowledgements}

This research is funded by the Natural Sciences and Engineering Research Council of Canada (NSERC) through the Discovery Grant program. WS is grateful for financial support provided through a University of Manitoba Graduate Fellowship and the GETS program from the Faculty of Graduate Studies. We thank Jorge Dourado (University of Manitoba) for assistance with the synthesis of the diacetylene. 
Table 1. Computed rotational constants $B_{e},{ }^{14} \mathrm{~N}$ nuclear quadrupole coupling constants in $\mathrm{MHz}$ and dipole moment in $\mathrm{D}$ of $\mathrm{HC}_{4} \mathrm{NCS}$ and $\mathrm{NC}_{3} \mathrm{NCS}$ at various levels of theory.

\begin{tabular}{c|cc|cc}
\hline \hline \multirow{2}{*}{} & \multicolumn{2}{|c|}{$\mathrm{HC}_{4} \mathrm{NCS}$} & \multicolumn{2}{c}{$\mathrm{NC}_{3} \mathrm{NCS}$} \\
& $\mathrm{H}-\mathrm{C}-\mathrm{C}-\mathrm{C}-\mathrm{C}-\mathrm{N}-\mathrm{C}-\mathrm{S}$ & $\mathrm{N}-\mathrm{C}-\mathrm{C}-\mathrm{C}-\mathrm{N}-\mathrm{C}-\mathrm{S}$ \\
\cline { 2 - 5 } & $\mathrm{MP} 2^{\mathrm{a}}$ & $\mathrm{CCSD}(\mathrm{T})^{\mathrm{b}}$ & $\mathrm{MP}^{\mathrm{a}}$ & $\mathrm{CCSD}(\mathrm{T})^{\mathrm{b}}$ \\
\hline$B_{e}$ & 588.4 & 586.5 & 589.1 & 585.2 \\
$e Q q(N C S)$ & 2.30 & 2.26 & 2.42 & 2.39 \\
$e Q q(N C)$ & 1 & 1 & -3.90 & -4.01 \\
$\mu$ & 1.26 & 1.65 & 4.24 & 3.75 \\
\hline \hline
\end{tabular}

${ }^{\mathrm{a}} \mathrm{cc}-\mathrm{pVQZ}$ basis set.

${ }^{\mathrm{b}} \mathrm{cc}-\mathrm{pVTZ}$ basis set. 
Table 2. Observed rotational transition frequencies of the parent and ${ }^{34} \mathrm{~S}$ singly substituted analog of $\mathrm{HC}_{4} \mathrm{NCS}$. The unresolved hyperfine components were fit to the same frequency as the one above.

\begin{tabular}{|c|c|c|c|c|c|c|c|}
\hline \multicolumn{8}{|c|}{$\mathrm{HC}_{4} \mathrm{NCS}$-parent } \\
\hline$J^{\prime}-J^{\prime \prime}$ & $F^{\prime}-F^{\prime \prime}$ & $v_{o b s} / \mathrm{MHz}$ & $\mathrm{o}-\mathrm{c} / \mathrm{kHz}$ & $J^{\prime}-J^{\prime \prime}$ & $F^{\prime}-F^{\prime \prime}$ & $v_{o b s} / \mathrm{MHz}$ & $\mathrm{o}-\mathrm{c} / \mathrm{kHz}$ \\
\hline \multirow[t]{3}{*}{$4-3$} & $5-4$ & 4760.7243 & -0.4 & $13-12$ & $14-13$ & 15472.3514 & 1.6 \\
\hline & $4-3$ & 4760.7419 & -0.1 & & $13-12$ & & -0.6 \\
\hline & $3-2$ & 4760.7900 & -0.9 & & $12-11$ & & -3.5 \\
\hline \multirow[t]{3}{*}{$5-4$} & $6-5$ & 5950.9134 & -0.9 & $14-13$ & $15-14$ & 16662.5212 & 1.5 \\
\hline & $5-4$ & 5950.9297 & 3.5 & & $14-13$ & & -0.4 \\
\hline & $4-3$ & 5950.9503 & -3.0 & & $13-12$ & & -3.0 \\
\hline \multirow[t]{3}{*}{$6-5$} & $7-6$ & 7141.1000 & -0.7 & $15-14$ & $16-15$ & 17852.6886 & 1.6 \\
\hline & $6-5$ & 7141.1114 & 1.9 & & $15-14$ & & 0.0 \\
\hline & $5-4$ & 7141.1264 & -0.3 & & $14-13$ & & -2.2 \\
\hline \multirow[t]{3}{*}{$7-6$} & $8-7$ & 8331.2826 & -2.4 & $16-15$ & $17-16$ & 19042.8533 & 1.8 \\
\hline & $7-6$ & 8331.2948 & 3.1 & & $16-15$ & & 0.3 \\
\hline & $6-5$ & 8331.3064 & 2.8 & & $15-14$ & & -1.6 \\
\hline \multirow[t]{3}{*}{$8-7$} & $9-8$ & 9521.4677 & 0.4 & $17-16$ & $18-17$ & 20233.0147 & 1.5 \\
\hline & $8-7$ & & -4.9 & & $17-16$ & & 0.2 \\
\hline & $7-6$ & 9521.4825 & 1.1 & & $16-15$ & & -1.4 \\
\hline \multirow[t]{3}{*}{$9-8$} & $10-9$ & 10711.6481 & 0.3 & $18-17$ & $19-18$ & 21423.1736 & 1.8 \\
\hline & $9-8$ & & -4.0 & & $18-17$ & & 0.6 \\
\hline & $8-7$ & 10711.6615 & 2.7 & & $17-16$ & & -0.8 \\
\hline \multirow[t]{3}{*}{$10-9$} & $11-10$ & 11901.8259 & -0.5 & $19-18$ & $20-19$ & 22613.3287 & 1.6 \\
\hline & $10-9$ & & -4.0 & & $19-18$ & & 0.5 \\
\hline & $9-8$ & 11901.8389 & 3.6 & & $18-17$ & & -0.8 \\
\hline $11-10$ & $12-11$ & 13092.0042 & 1.2 & 20-19 & $21-20$ & 23803.4797 & 0.8 \\
\hline
\end{tabular}




\begin{tabular}{cccc|cccc} 
& $11-10$ & & -1.8 & & $20-19$ & & -0.2 \\
& $10-9$ & & -6.1 & & $19-18$ & & -1.4 \\
$12-11$ & $13-12$ & 14282.1801 & 2.5 & & & \\
& $12-11$ & & 0.0 & & & \\
& $11-10$ & & -3.6 & & & & \\
\hline \multicolumn{7}{c}{$\mathrm{HC}_{4} \mathrm{NCS}-{ }^{34} \mathrm{~S}$} \\
\hline$J^{\prime}-J^{\prime \prime}$ & $F^{\prime}-F^{\prime \prime}$ & $v_{\text {obs }} / \mathrm{MHz}$ & $\mathrm{o}-\mathrm{c} / \mathrm{kHz}$ & $J^{\prime}-J^{\prime \prime}$ & $F^{\prime}-F^{\prime \prime}$ & $v_{\text {obs }} / \mathrm{MHz}$ & $\mathrm{o}-\mathrm{c} / \mathrm{kHz}$ \\
\hline $5-4$ & $6-5$ & 5806.7471 & -1.0 & $10-9$ & $9-8$ & 11613.5064 & 3.3 \\
& $5-4$ & 5806.7623 & 2.6 & $11-10$ & $12-11$ & 12774.8404 & 2.1 \\
$6-5$ & $7-6$ & 6968.0994 & -1.9 & & $11-10$ & & -0.8 \\
& $6-5$ & 6968.1131 & 3.4 & & $10-9$ & & -4.9 \\
& $5-4$ & 6968.1261 & -0.3 & $14-13$ & $15-14$ & 16258.8597 & 2.8 \\
$7-6$ & $8-7$ & 8129.4505 & -1.8 & & $14-13$ & & 0.9 \\
& $6-5$ & 8129.4661 & -5.1 & & $13-12$ & & -1.5 \\
$8-7$ & $9-8$ & 9290.7995 & -2.0 & $15-14$ & $16-15$ & 17420.1940 & 2.2 \\
& $7-6$ & 9290.8133 & -1.8 & & $15-14$ & & 0.6 \\
$10-9$ & $11-10$ & 11613.4946 & 0.0 & & $14-13$ & & -1.5 \\
& $10-9$ & & -3.4 & & & & \\
\hline \hline
\end{tabular}


Table 3. Spectroscopic constants of the parent and ${ }^{34} \mathrm{~S}$ singly substituted species of $\mathrm{HC}_{4} \mathrm{NCS}$, and the parent of $\mathrm{NC}_{3} \mathrm{NCS}$.

\begin{tabular}{c|c|c|c}
\hline \hline Parameters & $\mathrm{HC}_{4} \mathrm{NCS}-$ parent & $\mathrm{HC}_{4} \mathrm{NCS}_{-}{ }^{34} \mathrm{~S}$ & $\mathrm{NC}_{3} \mathrm{NCS}$ \\
\hline$B_{0} / \mathrm{MHz}$ & $595.09300(3)$ & $580.67632(1)$ & $596.26344(2)$ \\
$D_{0} / \mathrm{Hz}$ & $7.50(6)$ & $7.12(11)$ & $19.71(4)$ \\
$e Q q(N C S) / \mathrm{MHz}$ & $2.27(6)$ & $2.36(9)$ & $2.39(4)$ \\
$e Q q(N C) / \mathrm{MHz}$ & $\backslash$ & $\backslash$ & $4.17(10)$ \\
$\#$ lines & 27 & 13 & 28 \\
$\mathrm{rms} / \mathrm{kHz}$ & 1.82 & 1.87 & 1.29 \\
\hline \hline
\end{tabular}


Table 4. Observed rotational transition frequencies of the parent species of $\mathrm{NC}_{3} \mathrm{NCS}$. The unresolved hyperfine components were fit to the same frequency as the one above.

\begin{tabular}{|c|c|c|c|c|c|c|c|c|c|}
\hline$J^{\prime}-J^{\prime \prime}$ & $F_{1}{ }^{\prime}-F_{1}{ }^{\prime}$, & $F^{\prime}-F^{\prime \prime}$ & $v_{o b s} / \mathrm{MHz}$ & $\begin{array}{c}\mathrm{o}-\mathrm{c} \\
/ \mathrm{kHz}\end{array}$ & $J^{\prime}-J^{\prime \prime}$ & $F_{l}{ }^{\prime}-F_{1}{ }^{\prime \prime}$ & $F^{\prime}-F^{\prime \prime}$ & $v_{o b s} / \mathrm{MHz}$ & $\begin{array}{c}\mathrm{O}-\mathrm{c} \\
/ \mathrm{kHz}\end{array}$ \\
\hline $4-3$ & $5-4$ & $6-5$ & 4770.1159 & -0.1 & $14-13$ & $13-12$ & $13-12$ & 16695.1629 & 0.9 \\
\hline \multirow[t]{7}{*}{$6-5$} & $5-4$ & $4-3$ & 7155.1326 & 1.9 & & & $14-13$ & & -1.4 \\
\hline & & $6-5$ & 7155.1570 & -0.8 & & $14-13$ & $14-13$ & & 0.1 \\
\hline & $6-5$ & $5-4$ & 7155.1204 & -0.4 & & & $15-14$ & & -0.8 \\
\hline & & $6-5$ & 7155.1765 & -1.7 & & $15-14$ & $16-15$ & & 1.6 \\
\hline & $7-6$ & $6-5$ & 7155.0887 & -1.2 & $15-14$ & $14-13$ & $14-13$ & 17887.6395 & 0.6 \\
\hline & & $7-6$ & 7155.1326 & 1.4 & & & $15-14$ & & -1.5 \\
\hline & & $8-7$ & 7155.1497 & -1.4 & & $15-14$ & $15-14$ & & 0.1 \\
\hline \multirow[t]{8}{*}{$7-6$} & $6-5$ & $5-4$ & 8347.6519 & 0.2 & & & $16-15$ & & -0.8 \\
\hline & & $7-6$ & 8347.6702 & -2.6 & & $16-15$ & $17-16$ & & 1.2 \\
\hline & $7-6$ & $6-5$ & 8347.6433 & -0.6 & $16-15$ & $15-14$ & $15-14$ & 19080.1084 & -0.2 \\
\hline & & $7-6$ & 8347.6824 & -0.8 & & & $16-15$ & & -2.2 \\
\hline & & 8-7 & 8347.6775 & 1.7 & & $16-15$ & $16-15$ & & -0.6 \\
\hline & $8-7$ & $7-6$ & 8347.6213 & -1.8 & & & $17-16$ & & -1.5 \\
\hline & & $8-7$ & 8347.6519 & 0.3 & & $17-16$ & $18-17$ & & 0.3 \\
\hline & & $9-8$ & 8347.6653 & -1.1 & $17-16$ & $16-15$ & $16-15$ & 20272.5695 & -1.4 \\
\hline \multirow[t]{6}{*}{$9-8$} & $8-7$ & $8-7$ & 10732.6875 & -1.8 & & & $17-16$ & & -3.2 \\
\hline & & $9-8$ & 10732.6948 & 1.8 & & $17-16$ & $17-16$ & & -1.6 \\
\hline & $9-8$ & $9-8$ & 10732.6948 & -0.4 & & & $18-17$ & & -2.5 \\
\hline & & $10-9$ & 10732.6948 & 1.3 & & $18-17$ & $19-18$ & & -1.0 \\
\hline & $10-9$ & $9-8$ & 10732.6655 & 2.5 & $18-17$ & $17-16$ & $17-16$ & 21465.0258 & 0.6 \\
\hline & & $11-10$ & 10732.6875 & -0.2 & & & $18-17$ & & -1.0 \\
\hline $10-9$ & $9-8$ & $9-8$ & 11925.1968 & 2.9 & & $18-17$ & $18-17$ & & 0.6 \\
\hline
\end{tabular}




\begin{tabular}{ccccc|ccccc} 
& & $10-9$ & & -0.5 & & & $19-18$ & & -0.4 \\
& $10-9$ & $10-9$ & & -1.0 & & $19-18$ & $20-19$ & \\
$11-10$ & & $11-10$ & & -0.4 & $19-18$ & $18-17$ & $18-17$ & 22657.4713 & 0.3 \\
& $10-9$ & $11-10$ & 13117.6983 & 1.2 & & & $19-18$ & \\
& $11-10$ & $11-10$ & & 1.7 & & $19-18$ & $19-18$ & -1.2 \\
$12-11$ & $11-10$ & $12-11$ & & 1.5 & & & $19-18$ & 0.3 \\
& $12-11$ & 14310.1932 & 1.3 & & $20-19$ & $21-20$ & -0.6 \\
& $12-11$ & & 2.3 & $20-19$ & $19-18$ & $19-18$ & 23849.9087 & 0.7 \\
$13-12$ & $12-11$ & $13-12$ & & 1.8 & & & $20-19$ & & -0.5 \\
& $13-12$ & $13-12$ & 15502.6820 & 0.8 & & $20-19$ & $20-19$ & 0.9 \\
& & & 2.2 & & & $21-20$ & 0.1 \\
& $14-13$ & & 1.4 & & $21-20$ & $22-21$ & 1.2 \\
\hline \hline
\end{tabular}

Figure 1. Plot of the $\mathrm{CNC}$ bending potentials of $\mathrm{HC}_{4} \mathrm{NCS}$ and $\mathrm{NC}_{3} \mathrm{NCS}$ from single point calculations at the MP2/cc-pVQZ level.

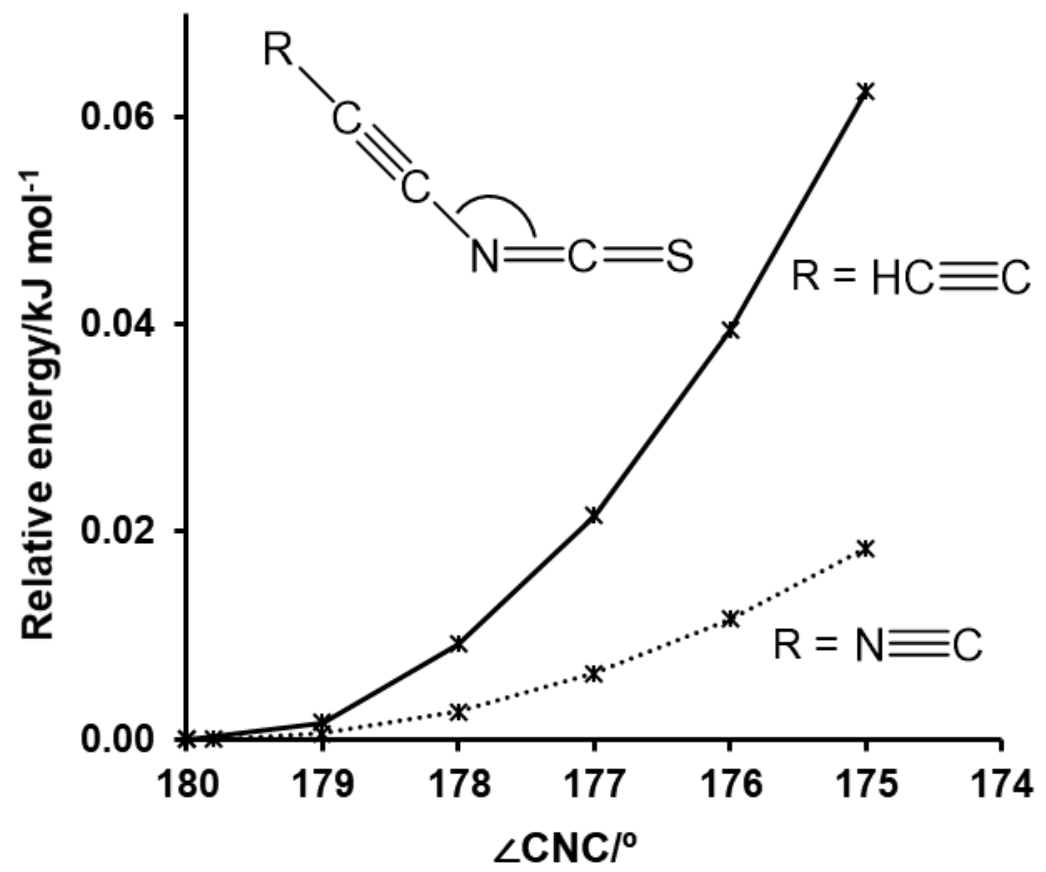


Figure 2. Example FTMW spectrum of the $J^{\prime}-J^{\prime \prime}=6-5$ rotational transition of the $\mathrm{HC}_{4} \mathrm{NCS}^{\prime}$ parent showing the assigned ${ }^{14} \mathrm{~N}$ hyperfine structure after averaging 3000 FIDs. The hyperfine components appear as Doppler doublets due to the instrument configuration.

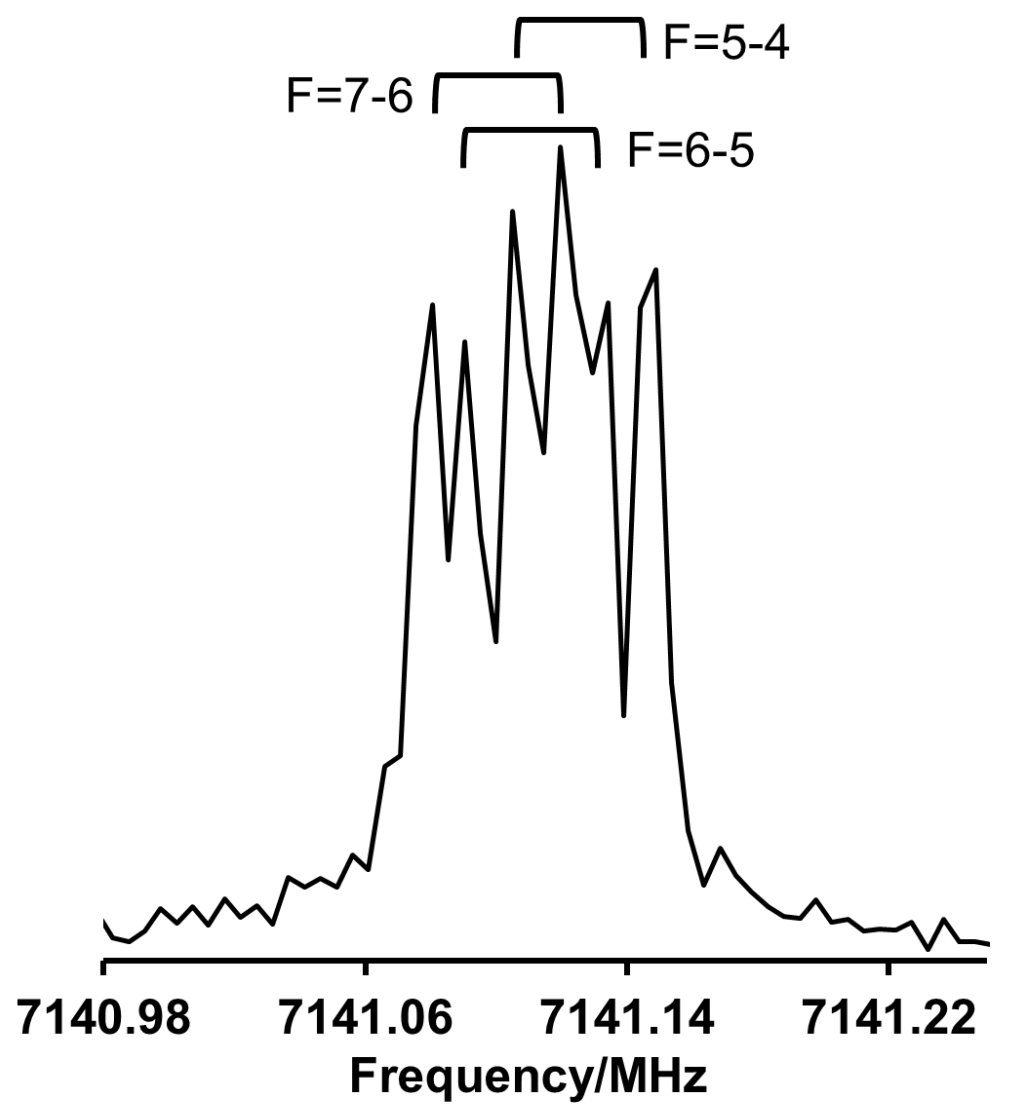


Figure 3. Sample FTMW spectrum (top) of the $J^{\prime}-J^{\prime \prime}=7-6$ rotational transition of the $\mathrm{NC}_{3} \mathrm{NCS}$ parent showing the assigned ${ }^{14} \mathrm{~N}$ hyperfine structure after averaging $32500 \mathrm{FIDs}$ and the simulated spectrum (bottom) based on the experimental constants. The hyperfine components appear as Doppler doublets due to the instrument configuration. 


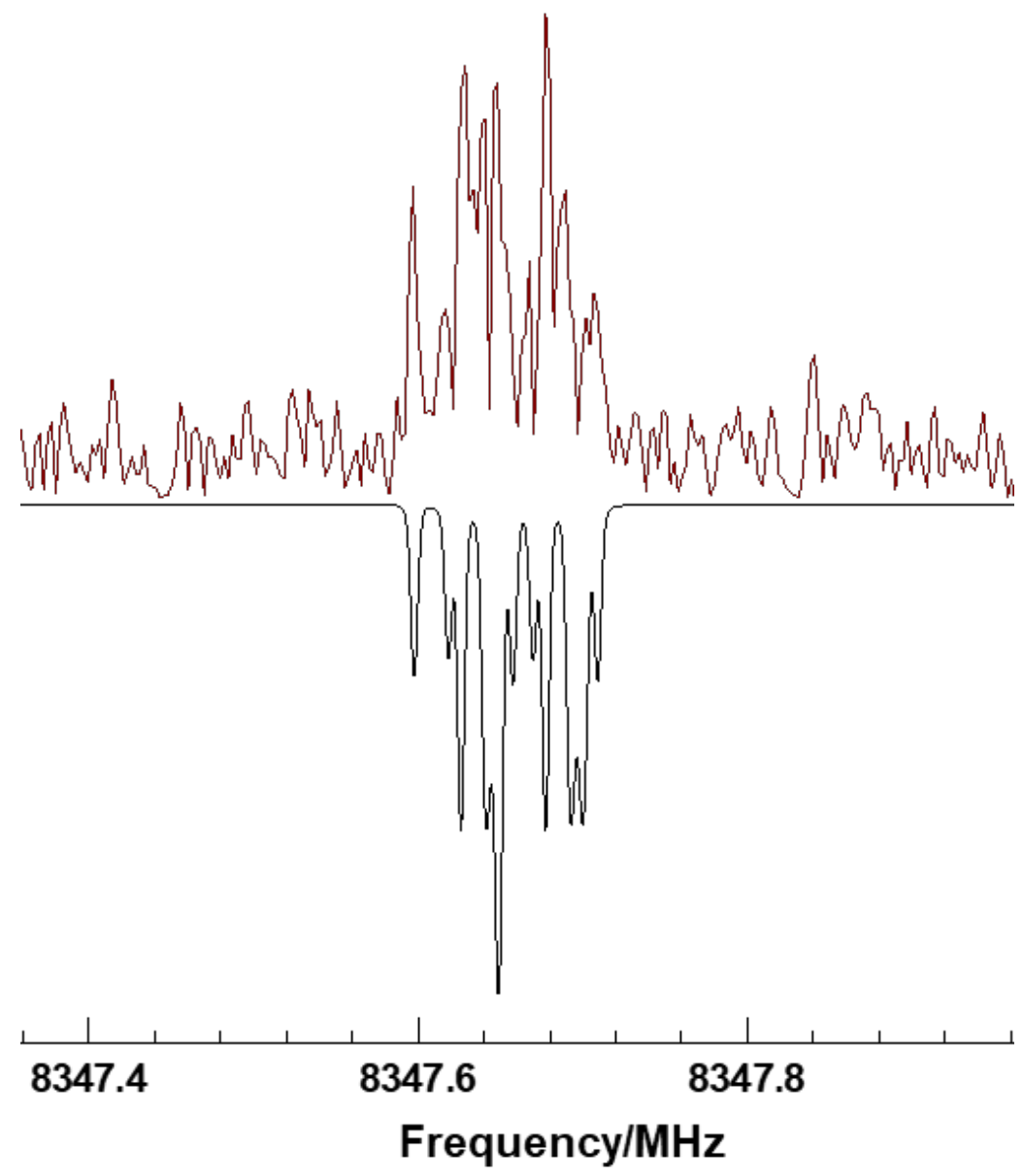

Figure 4. Log-log plot of the $D_{0} / B_{0}$ ratio as a function of chain length L (in $\AA$ ) for the cyanopolyynes $\mathrm{HC}_{2 \mathrm{n}+1} \mathrm{~N}$ (solid circles) and the title molecules $\mathrm{HC}_{4} \mathrm{NCS}$ (solid triangle), $\mathrm{NC}_{3} \mathrm{NCS}$ (solid square) 


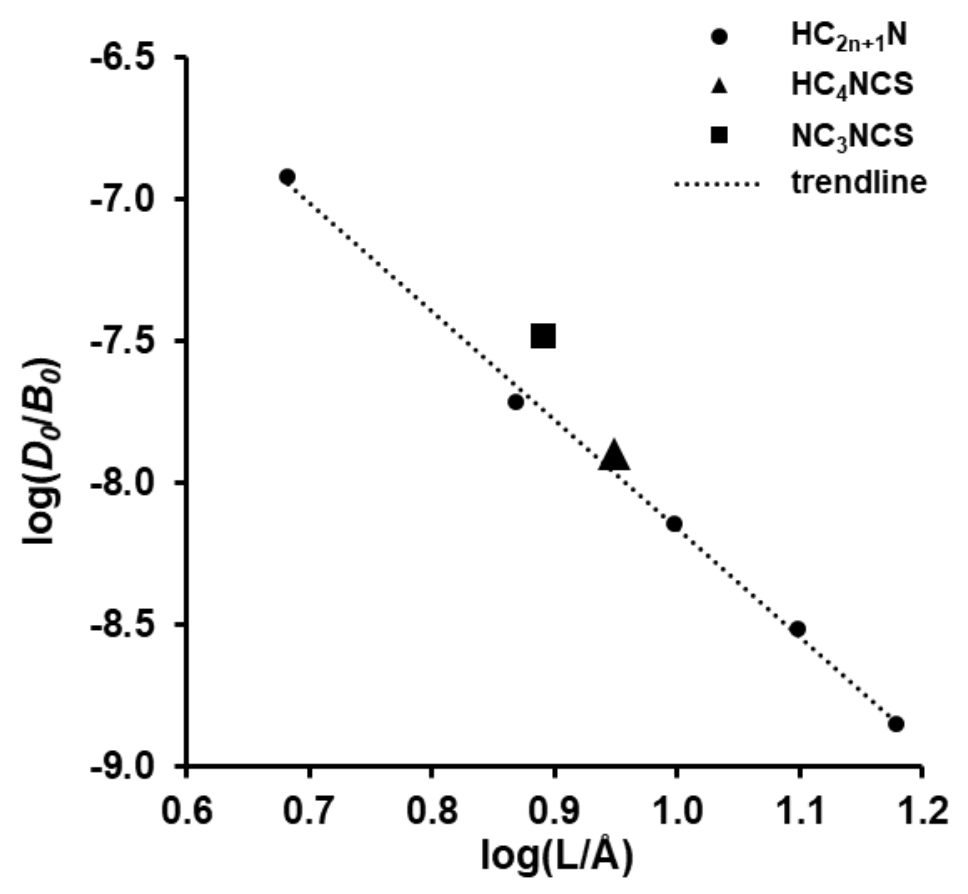

\section{References}

(1) Endres, C.P.; Schlemmer, S.; Schilke, P.; Stutzki, J.; Müller, H.S.P. The Cologne

Database for Molecular Spectroscopy, CDMS, in the Virtual Atomic and Molecular Data

Centre. VAMDC. J. Mol. Spectrosc. 2016, 327, 95-104.

(2) Frerking, M.A.; Linke, R.A.; Thaddeus, P. Interstellar Isothiocyanic Acid. Astrophys. J. 
1979, 234, L143-L145.

(3) Beard, C.I.; Dailey, B.P. The Structure and Dipole Moment of Isothiocyanic Acid. J. Chem. Phys. 1950, 18(11), 1437-1441.

(4) Halfen, D.T.; Ziurys, L.M.; Brünken, S.; Gottlieb, C.A.; McCarthy, M.C.; Thaddeus, P. Detection of a New Interstellar Molecule: Thiocyanic Acid HSCN. Astrophys. J. Lett. 2009, 702, 124-127.

(5) Brünken, S.; Yu, Z.; Gottlieb, C.A.; McCarthy, M.C.; Thaddeus, P. Laboratory Detection of Thiocyanic Acid HSCN. Astrophys. J. 2009, 706, 1588-1593.

(6) Wierzejewska, M.; Moc, J. Isomerization and Dissociation of CHNS: Quantum Mechanical Study. J. Phys. Chem. A. 2003, 107, 11209-11216.

(7) Durig, J.R.; Zheng, C.; Deeb, H. On the Structural Parameters and Vibrational Spectra of Some XNCS and XSCN (X=H, F, Cl, Br) Molecules. J. Mol. Struct. 2006, 784, 78-92.

(8) McGuire, B.A.; Martin-Drumel, M.-A.; Thorwirth, S.; Brünken, S.; Lattanzi, V.; Neill, J.L.; Spezzano, S.; Yu, Z.; Zaleski, D.P.; Remijan, A.J., et al. Molecular Polymorphism: Microwave Spectra, Equilibrium Structures, and an Astronomical Investigation of the HNCS Isomeric Family. Phys. Chem. Chem. Phys. 2016, 18, 22693-22705.

(9) Snyder, L.E.; Buhl, D. Observations of Radio Emission from Interstellar Hydrogen Cyanide. Astrophys. J. 1971, 163, L47-L52.

(10) Turner, B.E. Detection of Interstellar Cyanoacetylene. Astrophys. J. 1971, 163, L35-L39.

(11) Gottlieb, C.A.; Lada, C.J.; Gottlieb, E.W.; Lilley, A.E.; Litvak, M.M. Observations of Millimeter-wave HCN in Four Prototype Clouds. Astrophys. J. 1975, 202, 655-672.

(12) Broten, N.W.; MacLeod, J.M.; Oka, T.; Avery, L.W.; Brooks, J.W.; McGee, R.X.; Newton, L.M. Evidence for Weak Maser Action in Interstellar Cyanodiacetylene. 
Astrophys. J. 1976, 209, L143-L147.

(13) Avery, L.W.; Broten, N.W.; MacLeod, J.M.; Oka, T.; Kroto, H.W. Detection of the Heavy Interstellar Molecule Cyanodiacetylene. Astrophys. J. 1976, 205, L173-L175.

(14) Winnewisser, G.; Walmsley, C.M. The Detection of $\mathrm{HC}_{5} \mathrm{~N}$ and $\mathrm{HC}_{7} \mathrm{~N}$ in IRC +10216 . Astron. Astrophys. 1978, 70, L37-L39.

(15) Little, L.T.; Macdonald, G.H.; Riley, P.W.; Matheson, D.N. Observations of Interstellar $\mathrm{HC}_{5} \mathrm{~N}$ and $\mathrm{HC}_{7} \mathrm{~N}$ in Dark Dust Clouds. Mon. Not. R. Astron. Soc. 1978, 183, 45P-50P.

(16) Broten, N.W.; Oka, T.; Avery, L.W.; MacLeod, J.M.; Kroto, H.W. The Detection of $\mathrm{HC}_{9} \mathrm{~N}$ in Interstellar Space. Astrophys. J. 1978, 223, L105-L107.

(17) Rodriguez, L.F.; Chaisson, E.J. Observations of $\mathrm{HC}_{5} \mathrm{~N}$ and $\mathrm{HC}_{7} \mathrm{~N}$ in $\mathrm{Sgr} \mathrm{B} 2$ and Cloud 2. Mon. Not. R. astron. Soc. 1980, 192, 651-658.

(18) Sun, W.; Davis, R. L.; Thorwirth, S.; Harding, M. E.; van Wijngaarden, J. A Highly Flexible Molecule: The Peculiar Case of Ethynyl Isothiocyanate HCCNCS. submitted to $J$. Chem. Phys. A18.07.0135 (2018).

(19) King, M.A.; Kroto, H.W.; Landsberg, B.M. Microwave Spectrum of the Quasilinear Molecule, Cyanogen lsothiocyanate (NCNCS). J. Mol. Spectrosc. 1985, 113, 1-20.

(20) Winnewisser, B.P.; Winnewisser, M.; Medvedev, I.R.; Behnke, M.; De Lucia, F.C.; Ross, S.C.; Koput, J. Experimental Confirmation of Quantum Monodromy: The Millimeter Wave Spectrum of Cyanogen Isothiocyanate NCNCS. Phys. Rev. Lett. 2005, 95, 243002.

(21) Winnewisser, B.P.; Winnewisser, M.; Medvedev, I.R.; De Lucia, F.C.; Ross, S.C.; Koput, J. Analysis of the FASSST Rotational Spectrum of NCNCS in View of Quantum Monodromy. Phys. Chem. Chem. Phys. 2010, 12, 8158-8189.

(22) Winnewisser, M.; Winnewisser, B.P.; De Lucia, F.C.; Tokaryk, D.W.; Ross, S.C.; 
Billinghurst, B.E. Pursuit of Quantum Monodromy in the Far-infrared and Mid-infrared Spectra of NCNCS Using Synchrotron Radiation. Phys. Chem. Chem. Phys. 2014, 16, $17373-17407$.

(23) Johnson, A.W. 218. 2-Butyne-1 : 4-diol. Part I. Reactions of the Hydroxyl Groups. J. Chem. Soc. 1946, 0, 1009.

(24) Sedo, G.; van Wijngaarden, J. Fourier Transform Microwave Spectra of a "New" Isomer of OCS-CO 2. J. Chem. Phys. 2009, 131, 044303.

(25) Frisch, M. J.; Trucks, G. W.; Schlegel, H. B.; Scuseria, G. E.; Robb, M. A.; Cheeseman, J. R.; Scalmani, G.; Barone, V.; Mennucci, B.; Petersson, G. A.; et al. Gaussian 09, Revision B.01; Gaussian, Inc.; Wallingford, CT, 2010.

(26) Neese, F. The ORCA Program System, WIREs. Comput. Mol. Sci. 2012, 2, 73-78.

(27) Pavošević, F.; Neese, F.; Valeev, E.F. Geminal-Spanning Orbitals Make Explicitly Correlated Reduced-Scaling Coupled-Cluster Methods Robust, Yet Simple. J. Chem. Phys. 2014, $141,054106$.

(28) Pickett, H.M. The Fitting and Prediction of Vibration-Rotation Spectra With Spin Interactions. J. Mol. Spectrosc. 1991, 148, 371-377.

(29) Hocking, W.H.; Gerry, M.C.L.; Winnewisser, G. The Microwave and Millimetre Wave Spectrum, Molecular Constants, Dipole Moment, and Structure of Isocyanic Acid, HNCO. Can. J. Phys. 1975, 53, 1869-1901.

(30) Ross, S.C.; Cooper, T.A.; Firth, S.; Kroto, H.W.; Walton, D.R.M. The Microwave Spectrum and Semirigid Bender Analysis of Isocyanatoethyne, HC $\equiv$ CNCO. J. Mol. Spectrosc. 1992, 152, 152-167.

(31) Thaddeus, P.; McCarthy, M.C.; Travers, M.J.; Gottlieb, C.A.; Chen, W. New Carbon 
Chains in the Laboratory and in Interstellar Space. Faraday Discuss. 1998, 109, 121-135.

(32) Travers, M.J.; McCarthy, M.C.; Kalmus, P.; Gottlieb, C.A.; Thaddeus, P. Laboratory

Detection of the Linear Cyanopolyyne $\mathrm{HC}_{11} \mathrm{~N}$. Astrophys. J. 1996, 469, L65-L68.

(33) Chen, W.; McCarthy, M.C.; Novick, S.E.; Thaddeus, P. Microwave Spectra of the

Methylpolyynes $\mathrm{CH}_{3}(\mathrm{C} \equiv \mathrm{C})_{6} \mathrm{H}$ and $\mathrm{CH}_{3}(\mathrm{C} \equiv \mathrm{C})_{7} \mathrm{H}$. J. Mol. Spectrosc. 1999, 196, 335-337.

(34) Thaddeus, P.; McCarthy, M.C. Carbon Chains and Rings in the Laboratory and in Space. Spectrochim. Acta Part A 2001, 57, 757-774.

TOC Graphic

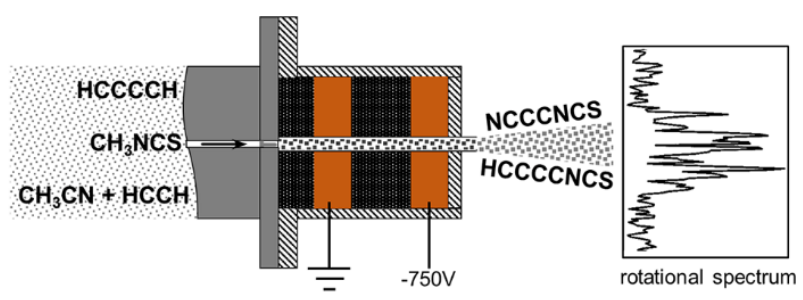


